\title{
Lung volume equipment and infection control
}

\author{
J.L. Clausen
}

\begin{abstract}
Lung volume equipment and infection control. J.L. Clausen. CERS Journals Ltd 1997. ABSTRACT: As part of the consensus workshop regarding lung volume measurements for the American Thoracic Society and European Respiratory Society, this background paper reviews mechanisms and risks of cross-infection resultant from performing measurements of absolute lung volumes either by body plethysmography, gas dilution, or gas wash-out techniques. Published reports of infection attributable to the performance of lung volume measurements are extremely rare. Nevertheless, because some infectious agents could be transmitted during measurements of lung volumes, and because of widespread concerns both of patients and some medical personnel about the risks of transmission of infections during inspiration from equipment used by other patients, a variety of measures have been advocated to minimize the risks of cross-infection.

Workshop participants were divided in opinion about whether such testing does indeed pose significant risk of cross-infection, and also could not agree regarding optimal measures to prevent cross-infection. Although there is conflicting information regarding the efficacy of particulate filters for protecting cross-contamination of downstream equipment and tubing, the author recommends that such filters be used when making lung volume measurements, but only if the filter has acceptably low resistance $\left(e . g\right.$. $\left.<0.15 \mathrm{kPa}^{-1} \cdot \mathrm{L}^{-1} \cdot \mathrm{s}\left(1.5 \mathrm{cmH}_{2} \mathrm{O}^{\cdot} \mathrm{L}^{-1} \cdot \mathrm{s}\right)\right)$, and the measurements are adjusted for the impact of the added resistance and dead space. Eur Respir J 1997; 10: 1928-1932.
\end{abstract}

\author{
Correspondence: J.L. Clausen \\ UCSD Medical Center MC\#8378 \\ 200 W. Arbor St. \\ San Diego \\ California \\ USA 92103 \\ Keywords: Cross-infection \\ hepatitis \\ human immunodeficiency virus \\ laboratory infection \\ lung volume measurements \\ plethysmography (whole body)
}

Received: February 181997

Accepted for publication February 221997

This publication evolved from a workshop on "measurement of lung volumes" convened by the European Respiratory Society and the American Thoracic Society, with additional support from the National Heart, Lung and Blood Institute (Grant No. HL 48384).
Although the devastating consequences of acquired immune deficiency syndrome (AIDS) as an outcome of infection with human immunodeficiency virus (HIV) have clearly been responsible for most of the current anxiety regarding the transmission of communicable diseases from pulmonary function testing, there are a number of diseases which are much more likely to be transmittable as a result of pulmonary function testing (e.g. hepatitis $\mathrm{B}$, tuberculosis, and varicella). It is the possibility of nosocomial transmission of these diseases, rather than AIDS, which should drive our efforts regarding the identification and implementation of optimal hygienic measures for pulmonary function testing.

Key factors which determine the communicability of diseases include: the sources of the organisms in patients (e.g. blood, saliva, faeces); the infective dose; the viability of the organism; routes of infectivity; and the susceptibility of potential hosts. The distinction between transmission of disease and transmission of disease vectors is important, and relates to the infective dose required to cause disease. Infective doses, however, are often quite variable between different subjects, and depend heavily upon the clinical condition and immune status of the potential recipients. For organisms such as HIV or hepatitis $\mathrm{B}$, which can cause potentially fatal diseases, research regarding infective doses is difficult, especially when there are large interspecies differences in disease susceptibility or limited animal models available. The issue of infective dose is also complicated by other factors, including the size of droplets in aerosols likely to be encountered during pulmonary function testing; the minimal infectious dose is less if contained within droplets of a size carried to airways beyond the ciliated epithelium [1].

There is no epidemiological evidence that HIV is transmitted from saliva or expired gases [2]. There is no clinical evidence that HIV can be transmitted via respiratory expirates. The very few cases of suspected transmission of HIV between dentists, paradental personnel and patients are considered most likely to have been secondary to transmission via blood rather than saliva [2-4]. We would expect reports of AIDS in kitchen employees and close patient contacts if saliva itself were a transmitter of HIV virus. The very low prevalence of HIV positivity in dental professionals without risk factors [3], as well as epidemiological evidence from close household contacts [2], strongly suggests that transmission of HIV via saliva is very unlikely to occur. However, fragments of HIV virus have been isolated from human saliva [5], so the possibility of transmission via saliva cannot be excluded with $100 \%$ certainty.

The mortality rate for all forms (A, B, Non-A/non-B or $\mathrm{C}$ and $\mathrm{D})$ of acute hepatitis is approximately $1 \%$. However, in patients with hepatitis B, about $3-5 \%$ of acute infections progress to chronic active hepatitis; and for non-A/non-B hepatitis, about $50-60 \%$ of patients progress to chronic active hepatitis, with cirrhosis in $20 \%$. It has been estimated that in the USA there are currently at least 30 times more deaths annually in healthcare workers due to occupationally acquired hepatitis B than to AIDS. 
The prevalence of asymptomatic hepatitis $\mathrm{B}$ virus (HBV) carriers in the USA is about $0.2 \%$, much lower than non-A, non-B hepatitis $(\sim 3 \%)$, but $20-30$ times higher than HIV. Hepatitis B is transmitted by a variety of routes. In acute hepatitis, there are high concentrations of viral antigens in the blood and a relatively high (12-17\%) risk of transmission of hepatitis B from accidental needle sticks. It is generally considered that saliva may be a route for transmission of hepatitis $B$, because HBV antigen has been identified in saliva and because saliva from patients with hepatitis B has been shown to cause disease in animals when injected percutaneously. However, oral ingestion of the virus can cause hepatitis only if the viral doses are high. There is no epidemiological or clinical evidence that $\mathrm{HBV}$ is transmitted from expired respiratory gases.

The transmission of rhinovirus is generally [6], but not always [7], considered to result from deposition of the virus on surfaces during respiratory manoeuvres, such as sneezing or coughing, and subsequent transmission to the recipient by inadvertent hand-to-nose manoeuvres. However, there is also convincing experimental evidence of aerosol transmission [7] between individuals in relatively close proximity, as well as reports of infections attributed to suboptimal ventilation systems in aeroplanes [8] or prisons [9].

Other pathogenic viruses, which may be excreted in respiratory tract secretions and which may cause disease when exposed to the respiratory tract mucosa of potential recipients, include: respiratory syncytial virus [10], varicella zoster (chicken pox), and measles [11].

There is no evidence that excretion of tubercle bacillus from salivary glands occurs in normal cases of tuberculosis. However, tuberculosis is clearly a communicable disease from transmission of organisms suspended in droplets, such as may be generated during coughing (or possibly as a result of forced vigorous expirations) in patients with pulmonary tuberculosis $[12,13]$. Suspensions of droplets containing tubercle bacillus can remain infectious for hours, if the droplets are of sufficiently small size and the dose inhaled exceeds the critical dose required to cause disease. The increasing prevalence of multidrug-resistant tuberculosis infections has increased concern about cross-infection of these organisms.

In addition to the potential risk of cross-infection originating from the testing of patients with recognized pathogens, organisms which frequently reside in respiratory tracts of healthy children and adults (e.g. Haemophilus influenzae, Branhamella catarrhalis, Pseudomonas aeruginosa) may be of special concern to immunosuppressed patients, as is the case for pathogens transmitted between susceptible patients (e.g. Pseudomonas cepacia, a bacterium which has been reported as a contaminant of spirometers [14], and which is particularly pathogenic in patients with cystic fibrosis).

Gold and Schwesinger [15] noted that, up to 1980, the Center for Communicable Disease (CDC) had received no reports of nosocomial transmission of disease from pulmonary function testing. Nevertheless, this does not negate the possibility that such transmission could occur. HAZALEus et al. [12] reported one case of skin test conversion attributed to spirometric testing on an instrument previously used on a patient with active tuberculosis. RUTALA et al. [16] reported bacterial contamination of pulmonary function equipment during testing, and noted bacterial contamination on $92 \%$ of mouthpieces, $50 \%$ of proximal tubing, and $0 \%$ from samples taken within a volume displacement spirometer connected to the mouthpiece and tubing (of unspecified length). Their results were similar to those reported by DEPLEDGE and BARRETT [17]. These data suggest that disinfection of mouthpieces and tubing between testing of patients may suffice for control of disease transmission from pulmonary function testing.

Prevention of nosocomial transmission of pathogens from equipment used for measuring lung volumes can, theoretically, be accomplished by a number of different approaches: all of the equipment surfaces in contact with the expired gases can be disinfected after testing of each patient; only disposable equipment can be used; or a filter effective in entrapping pathogens can be placed between the patient and the equipment. Each of these approaches has been advocated and each has significant limitations.

Disinfection of all equipment surfaces exposed to the expirate is difficult for some components (e.g. pressure transducers and shutters in plethysmographs, valves, gas analysers) used to measure lung volumes. It is generally not considered economically feasible to perform such disinfection between patients unless it is limited to those components closest to the patient (i.e. mouthpieces and tubing). Disposable systems, using principally bag-inthe-box measurements, are feasible for spirometry and rebreathing types of gas dilution techniques $[17,18]$, but are less feasible for whole-body plethysmography. In addition, this approach may entail significant variations from conventional testing methodology, requiring: replacement of existing equipment; the expense of retraining technical staff; and, possibly, technique-specific predictive values and changes in the clinical interpretation of test results.

The appropriate placement of filters with $100 \%$ effectiveness for trapping pathogenic organisms (both viruses and bacteria) from expirates during pulmonary function testing would appear to be the most practical method for eliminating transmission of pathogenic organisms between patients. The feasibility of this approach is, however, limited by problems in achieving $100 \%$ filtration rates for particles of viral size (e.g. $0.017 \mu \mathrm{m}$ diameter) without increasing the resistance and/or dead space of the testing circuit to levels that will interfere with testing. Alternatively, less than $100 \%$ efficacy can be tolerated if the transmission rate is below the infective dose necessary to cause disease. Some increase in instrument resistance and dead space can be tolerated if appropriate adjustments are made in the calculations that depend on these variables. Although larger increases in resistance and dead space can, theoretically, be corrected for mathematically, these alterations may cause physiological changes in respiration, which may invalidate the results or require that we redefine the limits of normality and disease severity.

Publications regarding the effects on the results of lung volume measurements from using filters during the testing are relatively few. GuImOND and Gibson [19] noted resistances of filters ranging $0.02-0.54 \mathrm{kPa} \cdot \mathrm{L}^{-1} \cdot \mathrm{s}$ $\left(0.22-5.35 \mathrm{cmH}_{2} \mathrm{O} \cdot \mathrm{L}^{-1} \cdot \mathrm{s}\right)$ at a flow of $8 \mathrm{~L} \cdot \mathrm{s}^{-1}$, when six filters were compared. When moistened from $10 \mathrm{~min}$ of 
rebreathing, introduction of these filters reduced peak expiratory flow by $1-21 \%$ and forced expiratory volume in one second (FEV1) by 1-13\% [19]; the effects of the filters on measurements of absolute lung volumes were not tested. JoHNS et al. [20] tested the effects of introducing a disposable microaerosol barrier filter (Pall Pro-Tec filter PF30S; Pall Biomedical Products Corp., Glen Cove, NY, USA) into the testing circuit using patients as well as normal subjects. The mean resistance after use was $0.055 \mathrm{kPa} \cdot \mathrm{L}^{-1} \cdot \mathrm{s}\left(0.56 \mathrm{~cm} \cdot \mathrm{H}_{2} \mathrm{O} \cdot \mathrm{L}^{-1} \cdot \mathrm{s}\right)$. No differences in measurements of lung volumes by single breath helium dilution or body plethysmography were noted when measurements were compared with and without the filters in the circuits (there were statistically significant decrements in the FEV 1 and peak expiratory flow (PEF) but the decrements were not clinically significant). Similarly, Fuso et al. [21] noted no effect of a Spirobac (DAR Spa, Italy) filter on plethysmographic measurements of total lung capacity (TLC) and residual volume (RV). Forced vital capacities (FVCs), FEV1, airway resistance (Raw) and specific airway conductance ( $\mathrm{s} G$ aw) were statistically significantly different from measurements without the filter, but the differences would have minimal clinical impact.

It is not surprising, given the paucity of reports of nosocomial transmission of disease from pulmonary function testing, that it was not possible to find any convincing reports of reduction of transmission of communicable diseases from the use of filters during pulmonary function testing. In the report by Gough et al. [22], intermittent outbreaks of infections with a specific strain of Haemophilus influenzae did not recur after installation of a one-way valve mouthpiece and in-line bacterial filter into the spirometer used for pulmonary function testing on the ward, but the evidence implicating the spirometer for the earlier infections was not strong (e.g. the organism was never recovered from the spirometer tested before installation of the filter).

Similarly, it was not possible to find reports of the effectiveness of such filters in reducing or eliminating the chances of nosocomial transmission of disease when used in the manoeuvres made during measurements of absolute lung volumes. There are a few reports of the effectiveness of filters when used for forced expiratory manoeuvres as part of spirometry; their conclusions, however, differ. KIRK et al. [23] concluded that a Pall Barrier filter (PF30, Pro-Tec) was $99.9 \%$ effective, when bacterial colony counts on blood agar after expirates passed through the filters were compared with the recoverable bacterial counts from the filter. In contrast, LeEming et al. [24] noted that both for the Collins DC1 Warren E. Collins Inc., Braintree, MA, USA and a Pall PF-305 filters, the efficacy of the filters in removing bacteria from expirates was only $\sim 67 \%$, when colony counts of expirates were compared with and without a filter in place [24]. It should be noted, however, that neither study addressed the critical issue: the effectiveness of the filters in minimizing or eliminating the aspiration of previously deposited or aerosolized bacteria or viruses during inspirations by patients tested subsequently. Furthermore, existing studies have failed to assess how the filtration rate for organisms in expirates compares with the worst-case concentration of pathogenic organisms and worst-case infective doses required to cause disease, criteria which, admittedly, are usually difficult to define.

\section{Workshop meeting discussions and interim consensus views}

Because of the paucity of credible reports of transmission of communicable disease from pulmonary function testing, only one participant was of the opinion that physiological measurements of lung volumes were associated with enough risk of transmission of communicable disease to warrant steps such as the use of disposable and/or bag-in-the-box systems [18], or disinfection of equipment between patients. Moreover, even if it was accepted that transmission of communicable diseases could occur during measurements of lung volumes, when workshop participants discussed the option of using filters between the patient and equipment, no consensus could be reached that the use of such filters would indeed be an effective method of preventing transmission of communicable disease.

There was similar spirited discussion of commonly cited laboratory practices of cleaning and disinfecting stopcocks and valves at the end of each testing day, or of draining and disinfecting water-filled spirometers once a week. It was recognized that such steps should help reduce the colonization of equipment with pathogenic bacteria. However, since it is widely accepted that a spirometer should be thoroughly cleaned and disinfected after use on a patient with a known serious communicable disease such as multidrug-resistant tuberculosis, some participants felt that reliance on once daily or weekly disinfection schedules was inadequate fo protecting patients tested on the same day as one or more patients with communicable disease not recognized at the time of testing.

Although the policy of Universal Precautions (undertaking all laboratory procedures as if each patient had a serious communicable disease) was embraced by all workshop participants for blood sampling, few endorsed the application of Universal Precautions during measurements of lung volumes. Although all participants endorsed standard steps to minimize transmission of communicable disease as cited below, few endorsed making mandatory other steps required for "honest" compliance with Universal Precautions (e.g. negative pressure ventilation; wearing of moulded surgical masks or other apparatus for respiratory protection by healthcare workers; disinfection, between each patient tested, of all surfaces within testing equipment exposed to expirates).

There was consensus, however, regarding the general rules of infection control presented in table 1 .

It should be noted that sterilization is defined as a procedure which destroys all microbial life, including highly resistant bacterial endospores, whereas disinfection inactivates virtually all recognized pathogenic microorganisms, but not necessarily all microbial forms (e.g. bacterial endospores) [25]. Methods of high-level disinfection commonly recommended as effective for inactivation of HBV and HIV include: 1) heat sterilization, using wet steam for $15 \mathrm{~min}$ at $121^{\circ} \mathrm{C}$ or dry steam for $60 \mathrm{~min}$ at $170^{\circ} \mathrm{C}$; 2) gas sterilization, using $450-500$ $\mathrm{mg} \cdot \mathrm{L}^{-1}$ ethylene oxide at $55-60^{\circ} \mathrm{C}$ for $20-30 \mathrm{~min}$; and 3) liquid sterilization, involving immersion for $30 \mathrm{~min}$ 


\section{Table 1. - General rules of infection control}

Disposable gloves should be worn when handling mouthpieces, when cleaning equipment exposed to saliva and sputum, and especially when drawing blood

Laboratory staff should wash hands prior to the testing of each patient

Periodic skin testing with purified protein derivative (PPD) of laboratory personnel

Administration of hepatitis B vaccine to laboratory staff if clinically indicated

Negative pressure ventilation for rooms where patients frequently cough during testing is preferable

When testing patients with recognized high-risk communicable diseases (e.g. tuberculosis, multidrug-resistant staphylococcus):

The clinical need for such testing should justify the risks Appropriate respiratory masks should be worn by laboratory staff

Accessible internal as well as external surfaces of equipment exposed to expirates should be washed and disinfected prior to testing of subsequent patients

Disinfection should ideally be performed by heat sterilization, but gas or liquid sterilization can be used if the equipment is well cleaned first (no droplets of saliva/sputum remain)

in a high-level disinfectant [26], such as $2 \%$ aqueous glutaraldehyde, $8 \%$ formaldehyde, $5.25 \%$ sodium hypochlorite (household bleach) diluted 1 to 10 , or $6-10 \%$ stabilized hydrogen peroxide. It should be noted that recommendations from the US Government's CDC (Atlanta, Georgia) for high-level disinfection of dental instruments [4] indicate that for effective disinfection, heat-sensitive instruments may require up to $10 \mathrm{~h}$ (rather than $30 \mathrm{~min}$ ) of exposure in a high-level sterilant/disinfectant. Laboratory testing of human T-lymphocyte virusIII (HTLV-III) has shown undetectable infectivity after only $1 \mathrm{~min}$ of exposure to $0.5 \%$ sodium hypochlorite. However, proteinatious accumulations in the nooks and crannies of intricate apparatus, such as dental instruments (or valves and pneumotachographs used for measuring lung volumes) are difficult to remove and require longer immersion times for disinfection. Obviously, nondisinfected deposits of pathogenic viruses on instruments such as dental drills that are used to cut tissue pose a substantially higher risk of disease transmission than a similar dried deposit on an internal surface of a pneumotachograph.

It is also important to note that, in addition to the corrosion of metals that chlorine- or peroxide-type disinfectants can cause, disinfectants are also associated with significant health problems if used improperly (e.g. release of chlorine gas from the mixing of bleach with acidic solutions, production of a carcinogen from mixing of bleach with formaldehyde, allergic and topical inflammatory reactions from exposure to glutaraldehyde).

Conclusions of the workshop participants are pending finalization of the consensus document, which will be published later.

\section{Author's recommendations regarding in-line filters}

Until better evidence is available, either proving or disproving the need for and the efficacy of filters in pul- monary function equipment, a clean droplet barrier filter should be used to protect all equipment in contact with expirates from patients, unless the equipment is sterilized or replaced between patients. This would be in accord with practices using ventilators [27, 28].

The resistance of the filter should be acceptably low (e.g. $\left.<0.15 \mathrm{kPa} \cdot \mathrm{L}^{-1} \cdot \mathrm{s}\left(1.5 \mathrm{cmH}_{2} \mathrm{O} \cdot \mathrm{L}^{-1} \cdot \mathrm{s}\right)\right)$, and the impact of such a filter should be assessed on the accuracy of the measurements. If the filter has a significant effect, the measurements must be adjusted accordingly. There is conflicting evidence regarding the efficacy of such filters for preventing the passage of bacteria or viruses; however, such filters will clearly prevent the aspiration of saliva and other fluid, which might otherwise be deposited or condensed in pulmonary function testing systems during testing on previous patients. This disquieting experience has occurred on at least two occasions in the author's laboratory and has been reported anecdotally by others. In the future, application of sophisticated techniques of cell wall protein analyses and other methods for typing specific bacteria and viruses could provide more convincing evidence for the need and efficacy of in-line droplet barrier filters during measurements of lung volumes (and other pulmonary function tests).

Mouthpieces, tubing, valves, and other equipment on the patient side of a viral filter or droplet barrier should be physically cleaned and sterilized (or disposed and replaced with clean components) between patients.

\section{References}

1. Sawyer WD. Airborne infection. Military Med 1963; 128: 90-97.

2. Friedland GH, Klein RS. Transmission of the human immunodeficiency virus. N Engl J Med 1987; 317: 11251135.

3. Klein RS, Phelan JA, Freeman K, et al. Low occupational risk of human immunodeficiency virus infection among dental professionals. N Engl J Med 1988; 318 : 86-90.

4. Centers for Disease Control and Prevention. Recommended infection control practices for dentistry. MMWR Morb Mort Wkly Rep 1986; 35: 238-243.

5. Groopman JW, Salahuddin SZ, Sarngadharan MG. HTLV-III in saliva of people with AIDS-related complex and healthy homosexual men at risk for AIDS. Science 1984; 26: 447-449.

6. Hendley JO, Wenzel RP, Gwaltney JM Jr. Transmission of rhinovirus colds by self-inoculation. $N$ Engl J Med 1973; 288: 1361-1364.

7. Dick EC, Jennings LC, Mink KA, Wartgow CD, Inhorn SL. Aerosol transmission of rhinovirus colds. J Infect Dis 1987; 156: 442-448.

8. Moser MR, Bender TR, Margolis HS, Noble GR, Kendal AP, Ritter DG. An outbreak of influenza aboard a commercial airliner. Am J Epidemiol 1979; 110: 1-6.

9. Hoge CW, Reichler MR, Dominguez EA, et al. An epidemic of pneumococcal disease in an overcrowded, inadequately ventilated jail. $N$ Engl J Med 1994; 331: 643-648.

10. Hall CB, Douglas RG Jr. Modes of transmission of respiratory syncytial virus. J Pediatrics 1981; 99: 100-103.

11. Remington PL, Hall WN, Davis IH, Herald A, Gunn RA. Airborne transmission of measles in a physician's office. J Am Med Assoc 1985; 253: 1574-1577.

12. Hazaleus RF, Cole J, Berdischewsky M: Tuberculin skin testing conversion from exposure to contaminated 
pulmonary function testing apparatus. Respir Care 1980; 26: $53-55$.

13. Riley RL. Disease transmission and contagion control. Am Rev Respir Dis 1982; 125 (3, part 2): 16-19.

14. Isles A, Maclusky I, Corey M, et al. Pseudomonas cepacia infection in cystic fibrosis: an emerging problem. $J$ Pediatrics 1984; 104: 206-210.

15. Gold PM, Schwesinger DW. Pulmonary laboratory infection control and safety. In: Clausen J, ed. Pulmonary Function Testing, Guidelines and Controversies. New York, Academic Press, 1980; p. 15.

16. Rutala DR, Rutala WA, Weber DJ, Thomann CA. Infection risks associated with spirometry. Infect Control Hosp Epidemiol 1991; 12: 89-92.

17. Depledge MH, Barrett A. Aseptic techniques for lung function testing. J Hosp Infect 1981; 2: 369-372.

18. Denison DM, Cramer DS, Hanson PJ. Lung function testing and AIDS. Respir Med 1989; 83: 133-138.

19. Guimond VJ, Gibson NN. Effect of in-line filters on spirometry. Can J Respir Ther 1990; 26: 9-11.

20. Johns DP, Ingram C, Booth H, Williams TJ, Walters EH. Effect of a microaerosol barrier filter on the measurement of lung function. Chest 1995; 107: 10451048.

21. Fuso L, Accardo D, Bevignani G, Ferrante E, Della Corte A, Pistelli R. Effects of a filter at the mouth on pulmonary function tests. Eur Respir J 1995; 8: 314-317.
22. Gough J, Kraak WAG, Anderson EC, Nichols WW, Slack MPE, McGhie D. Cross-infection by non-encapsulated Haemophilus influenzae. Lancet 1990; 336: 159-160.

23. Kirk YL, Kendall K, Ashworth HA, Hunter PR. Laboratory evaluation of a filter for the control of cross-infection during pulmonary function testing. J Hosp Infect 1992; 20: 193-198.

24. Leeming JP, Pryce-Roberts DM, Kendrick AH, Smith EC. The efficacy of filters used in respiratory function apparatus. J Hosp Infect 1995; 31: 205-210.

25. Favero MS. Sterilization, disinfection, and antisepsis in the hospital. In: Lennet EH, Balows A, Hausler WJ, Shadomy HJ, eds. Manual of Clinical Microbiology. 4th edn. Washington, DC, American Society for Microbiology, 1985; pp. 129-137.

26. Rutala WA. Selection and use of disinfectants in health care. In: Mayhall GC, ed. Hospital Epidemiology and Infection Control. London, Williams \& Wilkins, 1996; pp. 914-936.

27. Gallagher J, Strangeways JEM, Allt-Graham J. Contamination control in long-term ventilation; a clinical study using a heat- and moisture-exchanging filter. Anaesthesia 1987; 42: 476-481.

28. Lee MG, Ford JL, Hunt PB, Ireland DS, Swanson PW. Bacterial retention properties of heat and moisture exchange filters. Br J Anaesth 1992; 69: 522-525. 